International Journal of Biomedicine | June 2021 - Volume 11, Issue Suppl_1: Abstracts from the Third Russian International Conference "Cryo-electron microscopy 2021: achievements and prospects"

POSTER ABSTRACT PRESENTATIONS

SESSION TITLE: STRUCTURE AND FUNCTIONS OF THE TRANSCRIPTION AND TRANSLATION APPARATUS OF THE CELL

DOI: 10.21103/IJBM.11.Suppl_1.P26

\title{
Abstract P-26: Staphylococcus Aureus 30S Ribosomal Subunit in a Complex with the Era GTPase: Sample Preparation for Cryo-EM
}

Evelina Klochkova $^{1}$, Aydar Bikmullin ${ }^{1}$, Shamil Validov ${ }^{1}$, Natalia Garaeva ${ }^{1}$, Marat Yusupov $^{2}$, Konstantin Usachev ${ }^{1}$

${ }^{1}$ Institute of Fundamental Medicine and Biology, Kazan Federal University,

$$
\text { Kazan, Russia }
$$

${ }^{2}$ Institut de Génétique et de Biologie Moléculaire et Cellulaire, Université de Strasbourg, Illkirch, France

Background: An essential in bacteria GTPase Era is a multifunctional protein that is involved in cell cycle regulation and appears to play a significant role in ribosome biogenesis. It is required for the maturation of the $30 \mathrm{~S}$ ribosomal subunit.

Era consists of two domains: the GTPase N-terminal domain, conserved in the GTPase family, and a C-terminal RNA-binding $\mathrm{KH}$ domain. Era specifically binds to the 16S rRNA and stimulates processing of the small ribosomal subunit to its mature form.

Precise determination of nucleotide and amino acid sequences in the active site of binding will help in finding specific ways to prevent this interaction. In this way, it will be possible to disrupt the biogenesis of the ribosome and, thereby, stop or slow down protein synthesis in the bacterial cell. It is very important in the fight against pathogenic bacteria, such as Staphylococcus aureus (S. aureus). Methods: The His-tagged Era (His-Era) protein from S. aureus was expressed in E. coli BL21 strain and purified by Ni-NTA and SEC. The $30 \mathrm{~S}$ ribosomal subunits were collected after dissociation of the $S$. aureus $70 \mathrm{~S}$ ribosomes in sucrose gradient $(0-30 \%)$. Complex $30 \mathrm{~S}$-Era was obtained by mixing in vitro 30S subunits and His-Era, incubated for $15 \mathrm{~min}$ at $37^{\circ} \mathrm{C}$ and followed by NiNTA purification to remove unbound $30 \mathrm{~S}$ subunits. The presence of a stable 30S-Era complex has been confirmed by SDS-PAGE and agarose gel electrophoresis. The final sample quality was analyzed by negative staining EM. 
Results: For the first time in vitro 30S-Era complex from S. aureus was assembled and a sample was prepared for further structural studies by cryoelectron microscopy.

Key Words: GTPase $・$ Era $・$ ribosome $・ 30 \mathrm{~S}$ subunit $・$ Staphylococcus aureus

This work was supported by the Russian Science Foundation (Grant No. 2174-20034).

*Corresponding author: Evelina Klochkova. E-mail: evelina.klochkova@gmail.com

International Journal of Biomedicine. 2021;11 Suppl 1: S23.

doi: 10.21103/IJBM.11.Suppl_1.P26

(C)2021 International Medical Research and Development Corporation 